\title{
Effect of Salmon Fish on Lipid Profile of Male and Female Albino Rats
}

\author{
Serag El Din, O. S.; Batta, H. Abd El Azim and Abd El Fattah, N.
}

\section{Zoology Department, Women's College for Arts, Science and Education, Ain Shams University}

\begin{abstract}
Increased serum lipid levels are associated with the increased risk of many metabolic disorders including cardio vascular disease (CVD), obesity and diabetes mellitus. The objective of the current study was to determine whether feeding salmon diet with omega-3 polyunsaturated fatty acids (n-3 PUFAs) will alter serum lipid profile in male and female rats after three months of feeding. Although many studies have focused on the role of salmon fish on human health the results remain controversial. Consequently, the question of whether or not salmon fish are beneficial or harmful to lipid profile remains unresolved. Male and female Wistar albino rats were used in the present study. Each sex was randomly divided into two groups ( $\mathrm{n}=20$ per group). Control group: fed on the rodent diet AIN-93G which was recommended by the American Institute of Nutrition for growth, pregnancy and lactation. Salmon diet treated group: each rat was fed individually on cooked salmon fish diet $0.34-0.69 \mathrm{gm} / \mathrm{rat}$ which is equivalent to $200 \mathrm{gm} / 70 \mathrm{~kg}$ human body weight then were all given AIN-93G diet ad-libitum for three months. At the end of the experimental period the results showed that compared to the control group salmon diet significantly decreased serum levels of total cholesterol (TC) and triglycerides (TG) and significantly increased serum high-density lipoprotein (HDL-C) level however no effects were detected on serum low-density lipoprotein (LDL-C), glucose, insulin and body weight in male rats. Also in female rats salmon diet significantly decreased serum levels of TC and TG but no effect on HDL-C, LDL-C, glucose, insulin and body weight was observed. These results suggest that salmon meal play a protective role from cardio vascular disease (CVD) by decreasing lipid profile.
\end{abstract}

Key words: salmon, omega-3, lipid profile, body weight, albino rats.

\section{Introduction}

Fat has gained a reputation as a "bad" component of food with numerous adverse health effects. One has to think only of the terms, "saturated fat", "cholesterol", "trans-fatty acids" and "obesity" to realize the unhealthy reputation fat has gained in society. However, small amounts of dietary fat are essential for life and have a role not only as a potent source of calories but also as carrier of fat soluble vitamins, hormones and enzymes. 
Fats affect all body systems in some ways, but the cardiovascular system is the most affected one. One specific type of fatty acids (FAs) that has received great attention for its effects on the cardiovascular system is the PUFAs. The dietary habits of individuals have been shown to impact on heart health. Long term consumption of a diet containing high saturated fatty acids (SFAs) and low PUFAs has been found to be a primary cause of CVD (AIHW, 2001).

Generally FAs are hydrocarbon chains with a carboxyl group at one end and a methyl group at the other. Fat is increasingly recognized as a central feature of many biological processes. Dietary fat may influence a variety of physiological events in the human body and thereby could impact on the pathogenesis of various diseases. Properties of fat are influenced by FAs components. FAs are categorized into either saturated or unsaturated, depending on absence or presence of a carbon-tocarbon double bond respectively. Unsaturated fatty acids are further divided into two subgroups: monounsaturated fatty acids (MUFAs) containing only one double bond and PUFAs which harbor two or more double bonds.

The position of the first double bond is given by the (n-x) notation, counting the number of carbon atoms from the methyl end according to the international nomenclature. For example, omega-3, omega-6 and omega-9 (also referred as n-3, n-6 and n-9 fatty acids) denote from the methyl end respectively. The symbol C18:3 n-3 meaning FAs with 18 carbons, three double bonds and the first double bond is at the third carbon atom from the methyl end. In case of linoleic acid it is designated as C18:2 n- 6 because it has 18 carbons, two double bonds and the first double bond is at the sixth carbon atom from the methyl end. Docosahexaenoic acid (DHA, 22:6), eicosapentaenoic acid (EPA, 20:5) and $\alpha$-linolenic acid ( $\alpha$ LNA, 18:3) are the main n-3 PUFAs. Linoleic acid (LA, 18:2), arachidonic acid (AA, 20:4) and decosapentaenoic acid (DPA, 22:5) are the main n-6 PUFAs (Kolakowska et al., 2006).

MUFAs and SFAs are able to be synthesized by the body using dietary carbohydrates, proteins or other fats. However the body is not able to synthesis PUFAs, as it lacks the desatyrase enzymes necessary to form the n-3 and n-6 fatty acid double bonds. Because vertebrates are not able to synthesize n-3 or n-6 FAs, these must be supplied in the diet.

Theory dictates that human probably evolved on a diet containing a 1:1 ratio of n-6 to n-3 fatty acids yet modern times have produced typical Western diets that consist of a ratio between 10:1 and 25:1 and in some cases it may be as high as 40:1. Undoubtedly this imbalance has definitely contributed to several chronic health conditions and newer research is elucidating the role of proper FAs balance and intake in CVD (Simopoulos, 2002). 
Salmon fish meal provides a balanced nutritional content for various reasons. First it's high protein source which is around $20-60 \%$ and has great amino acids profile for fish, especially the ten essential amino acids (Watanabe, 2002). Secondly, salmon contains the necessary fatty acids. Also, fish meal is a highly digestible and palatable ingredient for fish. Moreover, salmon fish is low in antinutritional factors and carbohydrates (Zhou et al., 2004).

Also Weaver et $\boldsymbol{a l}$. (2008) found that salmon contained relatively high concentrations of n-3 PUFAs, low n-6: n-3 ratio, and favorable SFAs plus MUFAs to PUFAs ratio. Moreover the fish containing the highest amount of n-3 PUFAs are salmon with average levels of n-3 PUFAs (1112 gm EPA, 349 gm DPA and 2164 gm DHA for 100 gm of salmon fish). Mackerel and sardine also contain important amounts of n-3 with average levels of n-3 PUFAs (662 gm EPA, 118 gm DPA and 1404 gm DHA for $100 \mathrm{gm}$ of mackerel fish) and (638 gm EPA, 178 gm DPA and 1269 gm DHA for 100 gm of sardine fish) (Arab-Tehrany et al., 2012).

Although many studies have focused on the role of salmon fish on human health the results remain controversial, consequently the question of whether or not salmon fish are beneficial or harmful to human health remains unresolved.

Indeed, considerable interest has been focused on the role of n-3 on male fertility this interest has stemmed from numerous studies which found that n-3 PUFAs intake was associated with increased HDL cholesterol in healthy volunteers and patients with familial hyperlipidemia (Engler et al., 2004 and Dawczynski et al., 2010).

A decrease in both fasting and postprandial plasma TG levels were reported in older men and women fed a lower n-6 to n-3 PUFAs ratio compared to a higher n-6 to n-3 PUFAs ratio (Moore et al., 2006 and Sanders et al., 2006). Similarly, reduction in plasma TG levels and favorable changes in LDL size were associated with the lower n-6 to n-3 PUFAs ratio where subjects were fed n-6 to n-3 ratio of 3:1, 5:1 and 10:1 (Griffin et al., 2006). Moreover, Kelley et al. (2007) found that DHA supplementation reduced both the fasting and postprandial TG by more than $25 \%$ in hypertriglyceridemic men. Previous dietary intervention studies have also shown that n-3 PUFA is associated with lower LDL/HDL-cholesterol ratio in humans (Dawczynski et al., 2010). In addition, Skulas-Ray et al. (2011) found that subjects provided EPA and DHA (3.4 gm /day) for eight weeks significantly decreased serum TG level compared to subjects provided corn oil. However, vessby et al. (2001) noted significant increase in LDL in the individuals who received fish oil. On the other hand Zheng et al. (2014) stated that marine-derived $n-3$ polyunsaturated fatty acids have no protective effect on HDL and LDL. 
Taouis et al. (2002) demonstrated that a diet rich in $n-6$ PUFAs led to blunted signaling of insulin receptors while addition of $n-3$ PUFAs to the $n-6$ PUFAs based diet maintained insulin sensitivity. In addition, Flachs et al. (2014) showed that n-3 supplementation improved glucose and insulin homeostasis .However, Griffin et al. (2006) observed no effect of n-3 on serum glucose and insulin or insulin sensitivity in healthy individuals. On the other hand, Breslow (2006) observed that consumption of fish oil at $3 \mathrm{gm} /$ day cause hyperglycemia and increased LDL.

Also, animal studies are still controversial, Morgado et al. (2005) compared the effects of fish oil rich in n-3 PUFAs, sunflower oil rich in n-6 PUFAs, olive oil rich in n-9 PUFAs and coconut oil rich in SFAs on serum lipid profile in growing male Wister rats (age 8-10 weeks old) and found that plasma TC and TG, HDL and VLDL concentrations were significantly decreased in rats fed fish oil compared to sunflower oil, olive oil, and coconut oil.

Zampolli et al. (2006) reported a lower TG level in the fish oil fed group rich in n-3 PUFAs compared to the corn oil fed group rich in n-6 PUFAs after 20 weeks of dietary exposure in mice. Previous dietary intervention studies have also shown that n-3 PUFAs is associated with lower LDL/HDL-cholesterol ratio in rats (Vijaimohan et al., 2006). In addition, study in mice also reported a significantly lower plasma TC concentration in an n-3 PUFAs fed group compared to an n-6 PUFAs fed group after a one month feeding trial (Magdeldin et al., 2009).

On the other hand, some studies in mice reported no change in TG level when fed n-3 PUFAs diet (Riediger et al., 2008).Studies in mice have also reported no change in HDL- cholesterol level between n-3 PUFAs and n-6 PUFAs fed groups for 4 weeks (Zampolli et al., 2006), 20 weeks (Magdeldin et al., 2009) and for 32 weeks (Wang et al., 2009).

Another study used obese male rats fed either hypercholesterolemic diet or hypercholesterolemic diet supplemented with $5 \%$ total fat $(15 \% \mathrm{w} / \mathrm{w})$ as EPA/DHA derived from fish oil for 16 weeks and showed that fasting serum TC and TG were significantly decreased in rats fed the EPA/DHA supplemented diet, however, there were no significant effects on HDL and LDL fractions (Lu et al., 2011).

Micallef et al. (2009) confirmed that n-3 FAs supplementation lowered human body weight. Also, Munro and Garg (2013) found that obese women (but not men) had significantly reduced body weight and body mass index (BMI) after 4 weeks of supplementation with 6 gm/day fish oil (2040 mg/day n-3 PUFAs). However, DeFina et al. (2011) found no effect of n-3 on body weight. On the other hand, Nuernberg et al. (2011) reported a higher body weight in mice fed high fat diets rich in n-3 FAs and n-6 PUFAs compared to a control diet. 


\section{Materials and Methods}

Adult male and female Wistar albino rats approximately of the same age about 3 months old with average body weight 120 gm obtained from the private market Abou-Rawash, Giza, Egypt, were used in the present study. Each sex was randomly divided into two groups ( $n=20$ per group).Control group: fed on the basal diet (AIN-93G ad-libitum) according to (Reeves, 1997) and salmon diet treated group: each rat was fed individually on cooked salmon diet $0.34-0.69 \mathrm{gm} / \mathrm{rat}$ which is equivalent to $200 \mathrm{gm}$ $170 \mathrm{~kg}$ human body weight then were given AIN-93G diet ad-libitum for three months.

Weight of salmon diet changed according to the change in rat's weight. Each rat was transferred on individual cage for receiving their salmon diet.

Salmon diet was prepared and cooked according to (koubaa et al., 2012)

At the end of experiment, fasting blood samples were collected from the orbit plexus veins into clean dry centrifuge tubes .serum were separated and stored for biochemical analysis.

\section{1- Body weight:}

Body weights of rats were recorded before, during and after the experimental period.

2- Determination of fatty acids composition of salmon fish using by gas chromatography coupled with mass spectrometry (GC-MS) method according to (Bratu et al., 2013)

\section{3- Biochemical analysis:}

Determination of TC level in serum samples were measured by Synchron CX4 according to the method of (Roeschlau et al., 1974). HDL-C and LDL-C level were measured by Synchron CX4 according to (Gordon et al., 1977) also serum TG and glucose levels were estimated by Synchron CX4 depending on assay depicted by (Stein, 1987 and Tietz, 1995) respectively. Insulin was measured by the enzyme-linked immunosorbent assay (ELISA) kit according to (Judzewitsch et al., 1982).

\section{Statistical analysis:}

All data were analyzed using the SPSS for windows version 20.0 (Courtney, 2013). Independent sample t-test was used to calculate statistical significance between the control group and salmon diet treated group. The level of significance was set as $\mathrm{P}<0.05$ for all statistical tests. 


\section{Results}

Table (I): show: percentage of fatty acids composition in cooked salmon (\%/100gm)

\begin{tabular}{|c||c||}
\hline \multicolumn{1}{|c||}{ Fatty acids } & Cooked salmon diet \% \\
\hline C10:0 decanoic acid or capric aid (saturated) & 0.40 \\
\hline C12:0 Lauric acid (saturated) & 4.19 \\
\hline C14:0 myristic acid (saturated) & 8.93 \\
\hline C16:0 palmitic acid (saturated) & 17.94 \\
\hline C18:1(n-9, oleic acid) mono-un saturated & 29.62 \\
\hline C18:2 linoleic acid (n-6, LA) & 7.95 \\
\hline C18:3 linolenic (n-3, ALA) & 2.58 \\
\hline C20:4 arachidonic (n-6, AA) & 1.93 \\
\hline C20:5 eicosapentaenoic acid (n-3, EPA) & 13.30 \\
\hline C22:6 docosahexaenoic acid (n-3, DHA) & 13.16 \\
\hline Total saturated fatty acids & 31.46 \\
\hline Total unsaturated fatty acids & 68.54 \\
\hline Total n-3 & 29.04 \\
\hline Total n-6 & 9.88 \\
\hline n-3/n6 ratio & 2.94 \\
\hline
\end{tabular}

Data present in table (II) and illustrated in figs. (1a-1g): show effects of salmon diet on male rats lipid profile and body weight.

Salmon fish diet significantly decreased serum levels of TC and TG with $(-12.15 \%$ and $-14.68 \%)$ respectively and significantly increased serum level of HDL with (15.84\%) however no significant effects were detected on serum levels LDL, glucose, insulin and body weight as compared with control group.

Table (II): Effects of salmon diet on male rats lipid profile and body weight.

\begin{tabular}{|c|c|c|c|c|c|c|c|c|}
\hline \multicolumn{2}{|l|}{ Parameters } & TC (mg/dl) & $\begin{array}{c}\text { TG } \\
(\mathrm{mg} / \mathrm{dl})\end{array}$ & $\begin{array}{l}\text { HDL-C } \\
(\mathrm{mg} / \mathrm{dl})\end{array}$ & $\begin{array}{l}\text { LDL-C } \\
(\mathrm{mg} / \mathrm{dl})\end{array}$ & $\begin{array}{l}\text { glucose } \\
\text { (mg/dl) }\end{array}$ & $\begin{array}{l}\text { Insulin } \\
\text { (mIU/ ml) }\end{array}$ & $\begin{array}{l}\text { Body weight } \\
\text { (gm }\end{array}$ \\
\hline $\begin{array}{l}\text { Control group } \\
\qquad(\mathbf{n}=20)\end{array}$ & $\begin{array}{c}\text { Mean } \pm \\
\text { S.E }\end{array}$ & $125.95 \pm 1.54$ & $\begin{array}{r}103.00 \\
1.77\end{array}$ & $\begin{array}{c}39.89 \pm \\
2.30\end{array}$ & $\begin{array}{c}43.01 \pm \\
2.38\end{array}$ & $\begin{array}{c}98.46 \pm \\
3.20\end{array}$ & $\begin{array}{l}7.90 \pm \\
0.55\end{array}$ & $\begin{array}{c}225.30 \pm \\
3.07\end{array}$ \\
\hline $\begin{array}{l}\text { Salmon diet treated } \\
\text { group }(0.34-0.69 \mathrm{gm} . / \\
\text { rats }) \\
(\mathrm{n}=20)\end{array}$ & $\begin{array}{c}\text { Mean } \pm \\
\text { S.E }\end{array}$ & $110.65 \pm 5.69$ & $\begin{array}{c}87.88 \pm \\
2.43\end{array}$ & $\begin{array}{c}46.21 \pm \\
1.52\end{array}$ & $\begin{array}{c}39.57 \pm \\
1.43\end{array}$ & $\begin{array}{c}92.43 \pm \\
3.84\end{array}$ & $8.49 \pm 0.77$ & $\begin{array}{c}203.70 \pm \\
7.06\end{array}$ \\
\hline & $\begin{array}{c}\% \text { of } \\
\text { change }\end{array}$ & -12.15 & -14.68 & 15.84 & -7.10 & -6.12 & 7.47 & -9.59 \\
\hline & $P$ value & $\mathrm{P}<0.05$ & $\mathrm{P}<0.01$ & $\mathrm{P}<0.05$ & N.S. & N.S. & N.S. & N.S. \\
\hline
\end{tabular}




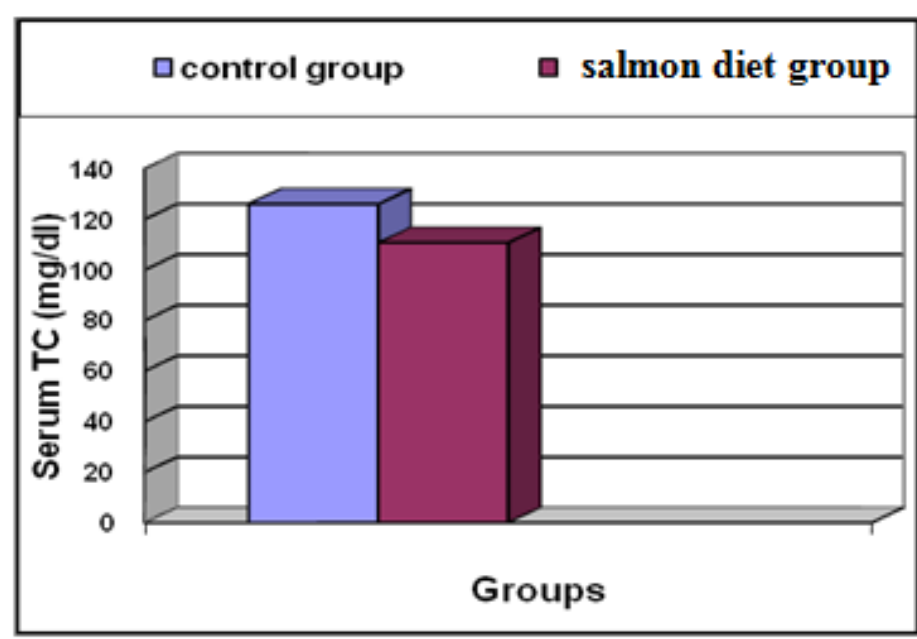

Fig (1a): Effect of salmon diet on TC level of male rats

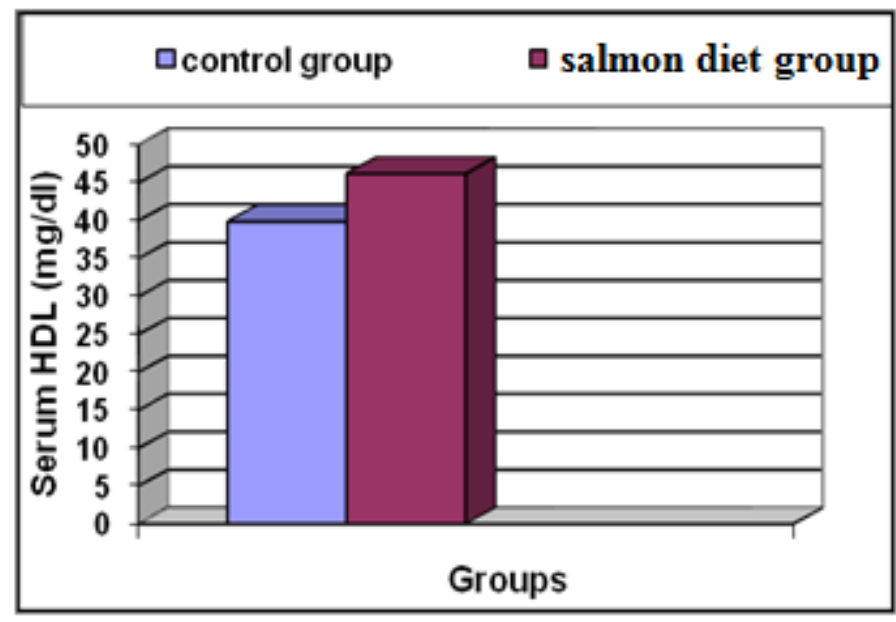

Fig (1c): Effect of salmon diet on HDL-C of male rats

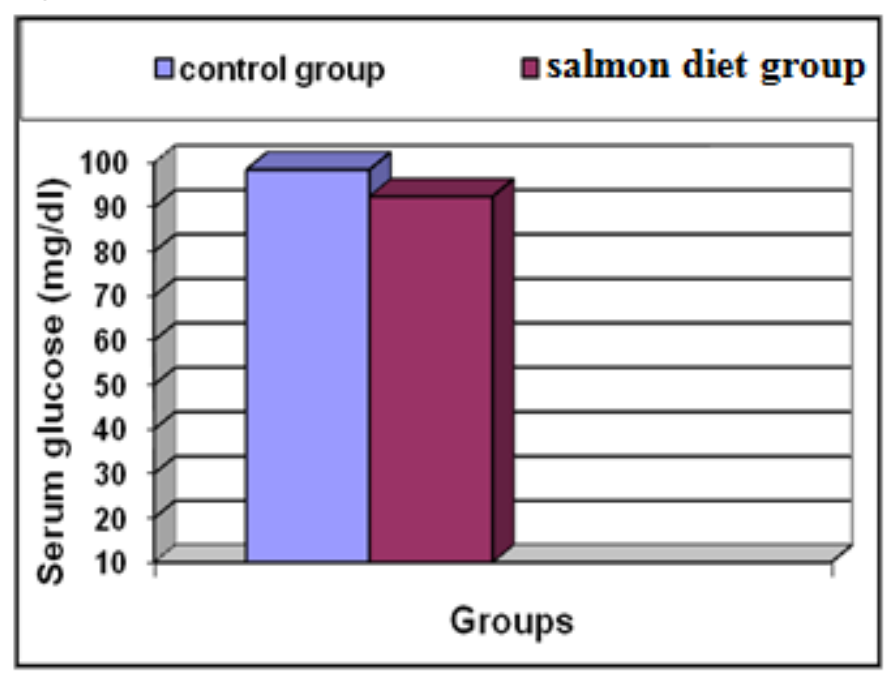

Fig (1e): Effect of salmon diet on glucose level of male rats

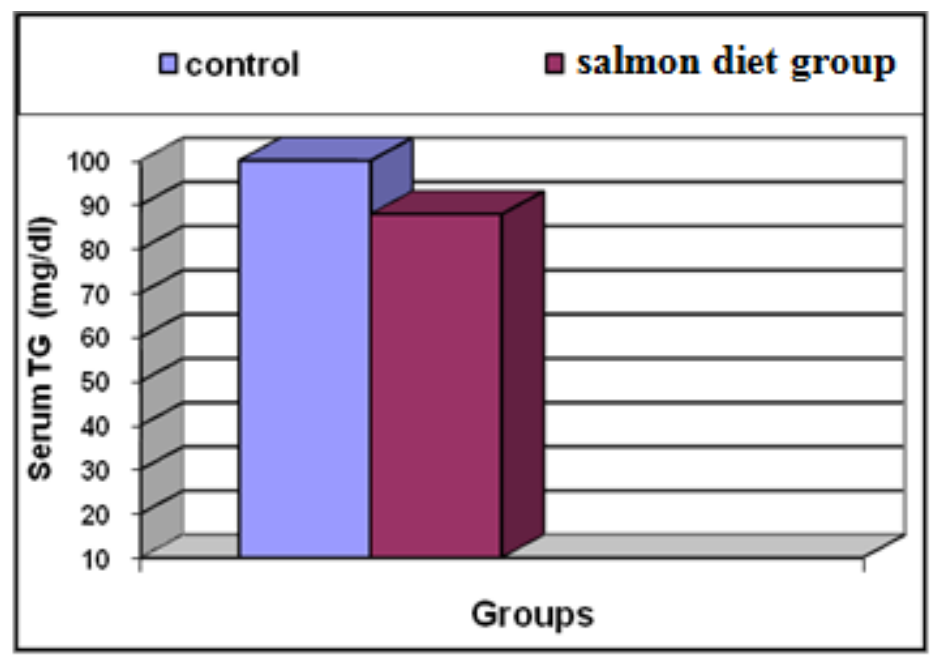

Fig (1b): Effect of salmon diet on TG level of male rats

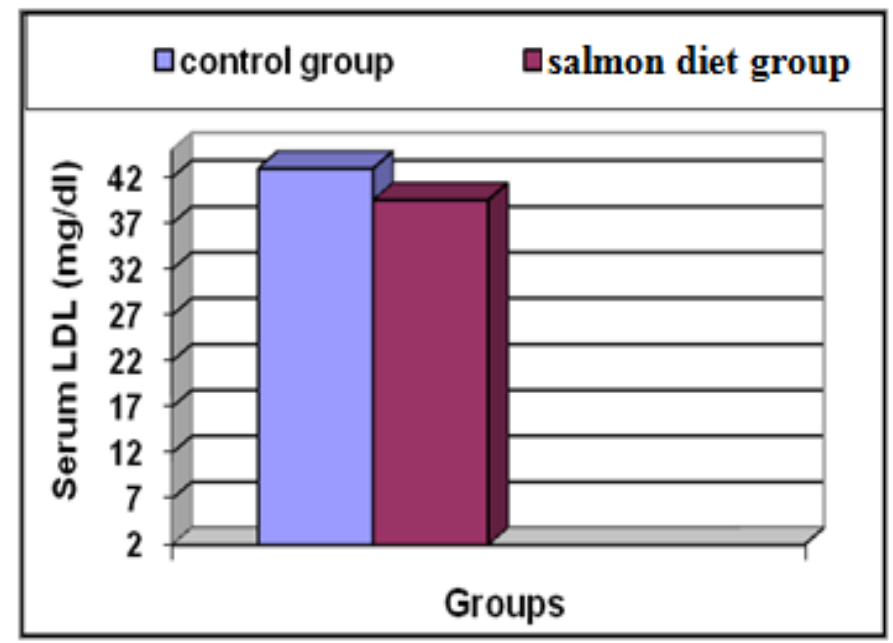

Fig (1d): Effect of salmon diet on LDL-C level of male rats

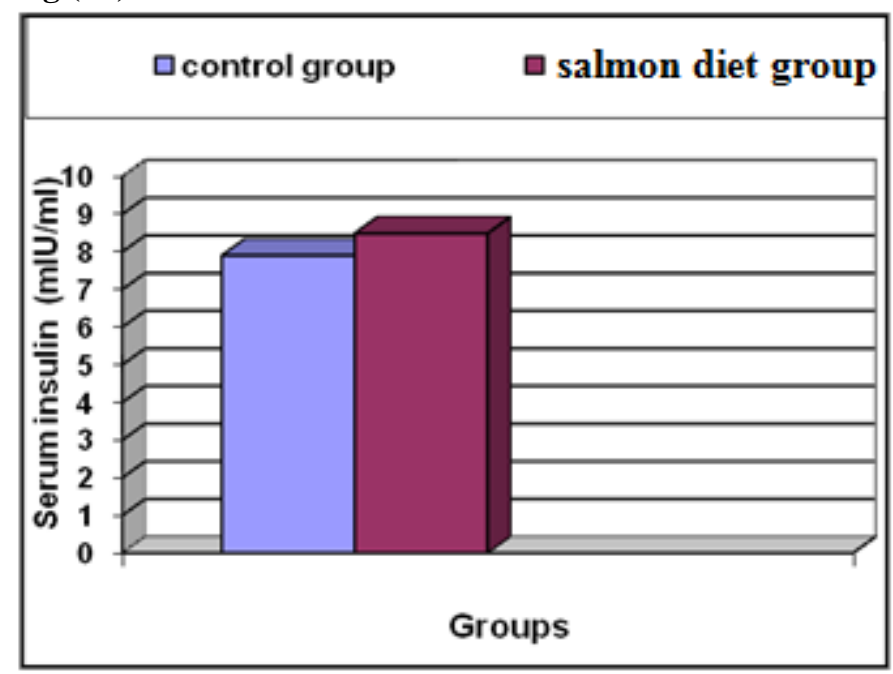

Fig (1f): Effect of salmon diet on insulin level of male rats 


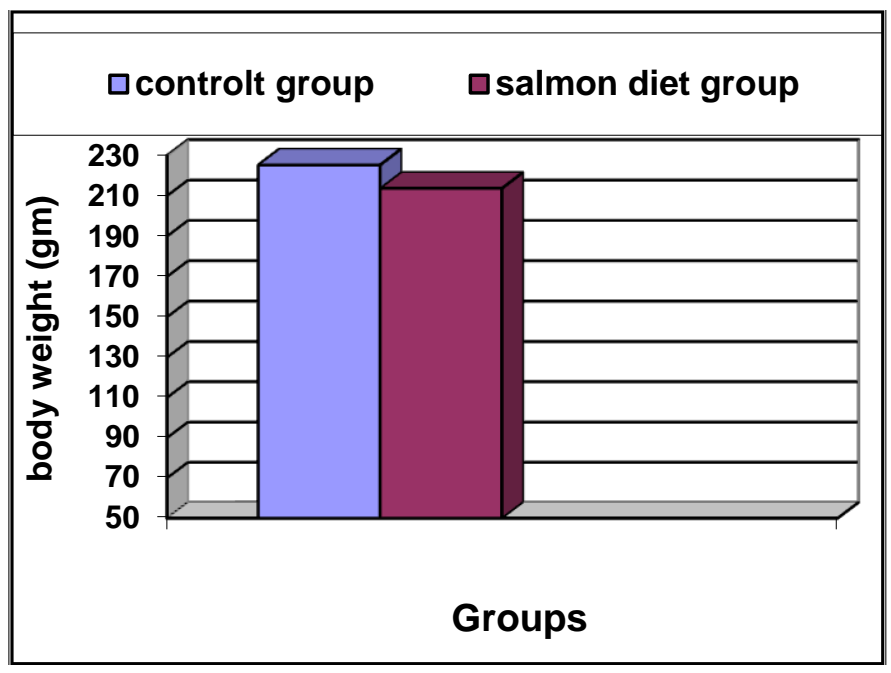

Fig (1g): Effect of salmon diet on body weight of male rats

Results found in table (III) and figures (2a-2g) show effects of salmon diet on female rats lipid profile and body weight.

Salmon fish induced significant decrease in serum level of TC and TG with $(-24.90 \%$ and $-15.92 \%)$ respectively but we didn't find any significant effect on levels of HDL, LDL, insulin, glucose and body weight compared with control group.

Table (III): Effects of salmon diet on female rats lipid profile and body weight.

\begin{tabular}{|c|c|c|c|c|c|c|c|c|}
\hline \multicolumn{2}{|c|}{ Groups } & TC (mg/dl) & TG (mg/dl) & $\begin{array}{l}\text { HDL-C } \\
\text { (mg/dl) }\end{array}$ & $\begin{array}{l}\text { LDL-C } \\
\text { (mg/dl) }\end{array}$ & $\begin{array}{l}\text { glucose } \\
\text { (mg/dl) }\end{array}$ & $\begin{array}{c}\text { Insulin } \\
\text { (mIU/ ml) }\end{array}$ & $\begin{array}{c}\text { Body weight } \\
\text { (gm) }\end{array}$ \\
\hline Control group & $\begin{array}{c}\text { Mean } \pm \\
\text { S.E }\end{array}$ & $\begin{array}{c}128.70 \pm \\
3.62\end{array}$ & $\begin{array}{c}96.96 \pm \\
4.39\end{array}$ & $\begin{array}{c}38.82 \pm \\
0.89\end{array}$ & $\begin{array}{c}55.79 \pm \\
4.45\end{array}$ & $\begin{array}{c}98.68 \pm \\
3.78\end{array}$ & $\begin{array}{c}9.92 \pm \\
0.49\end{array}$ & $\begin{array}{c}238.60 \pm \\
10.19\end{array}$ \\
\hline $\begin{array}{l}\text { Salmon group } \\
\begin{array}{c}(0.34-0.69 \\
\text { gm. / } \\
\text { rats })\end{array}\end{array}$ & $\begin{array}{c}\text { Mean } \pm \\
\text { S.E }\end{array}$ & $96.66 \pm 4.33$ & $\begin{array}{c}81.52 \pm \\
3.47\end{array}$ & $\begin{array}{c}42.36 \pm \\
1.79\end{array}$ & $\begin{array}{c}50.46 \pm \\
3.51\end{array}$ & $95.08 \pm 3.46$ & $10.73 \pm 0.94$ & $\begin{array}{c}222.20 \pm \\
10.39\end{array}$ \\
\hline & $\begin{array}{c}\% \text { of } \\
\text { change }\end{array}$ & -24.90 & -15.92 & 9.12 & -9.55 & -3.65 & 8.16 & -6.87 \\
\hline & $P$ value & $P<0.001$ & $\mathrm{P}<0.05$ & N.S. & N.S. & N.S. & N.S. & N.S. \\
\hline
\end{tabular}




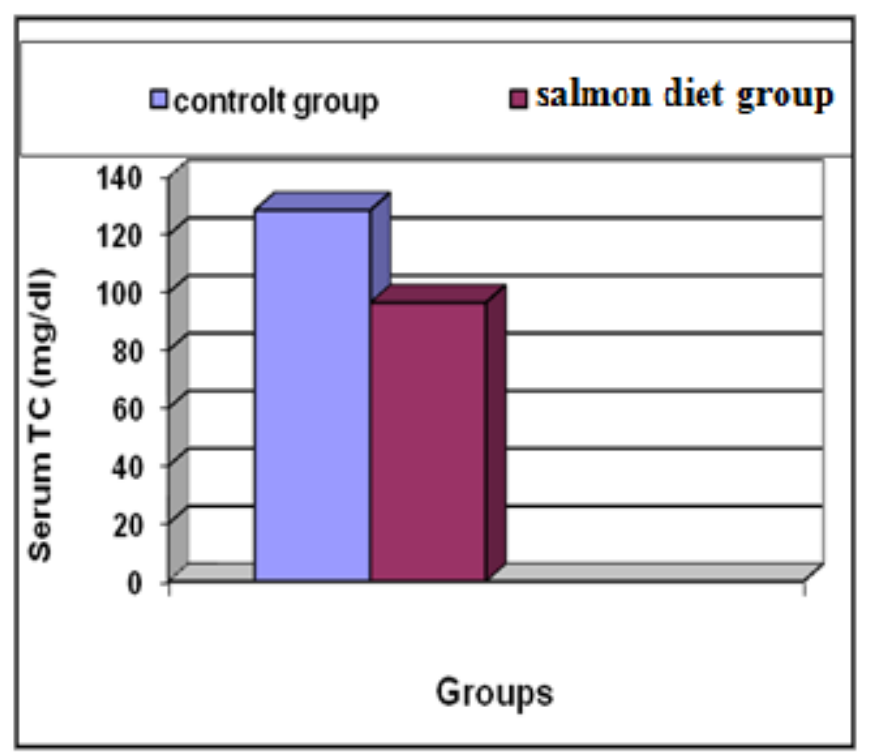

Fig (2a): Effect of salmon diet on TC level of female rats

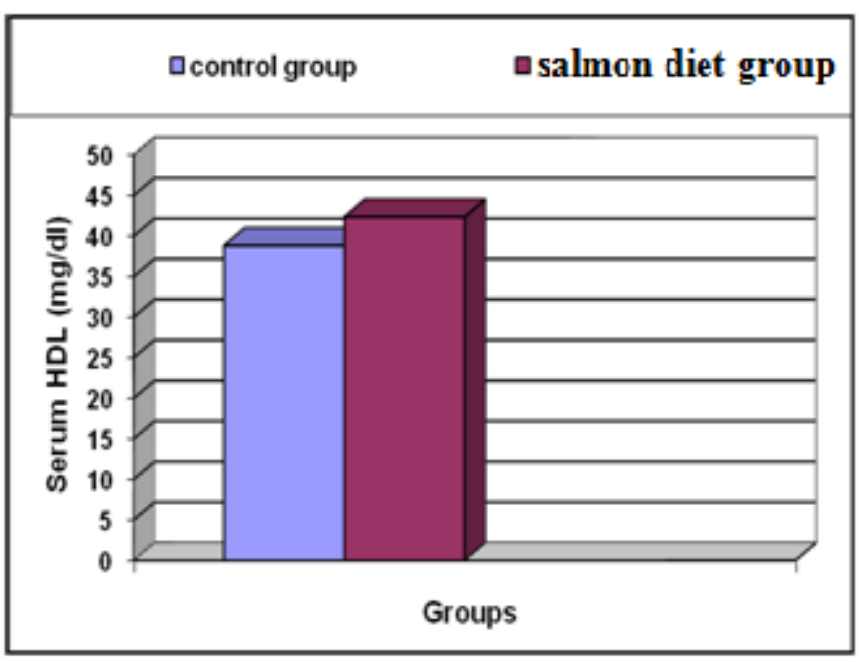

Fig (2c): Effect of salmon diet on HDL-C level of female rats

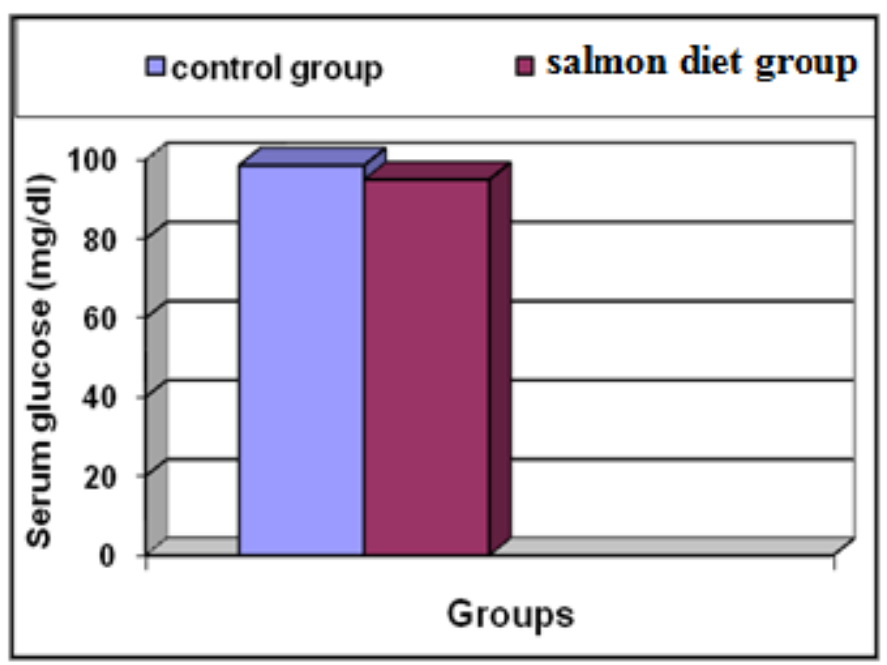

Fig (2e): Effect of salmon diet on glucose of female rats

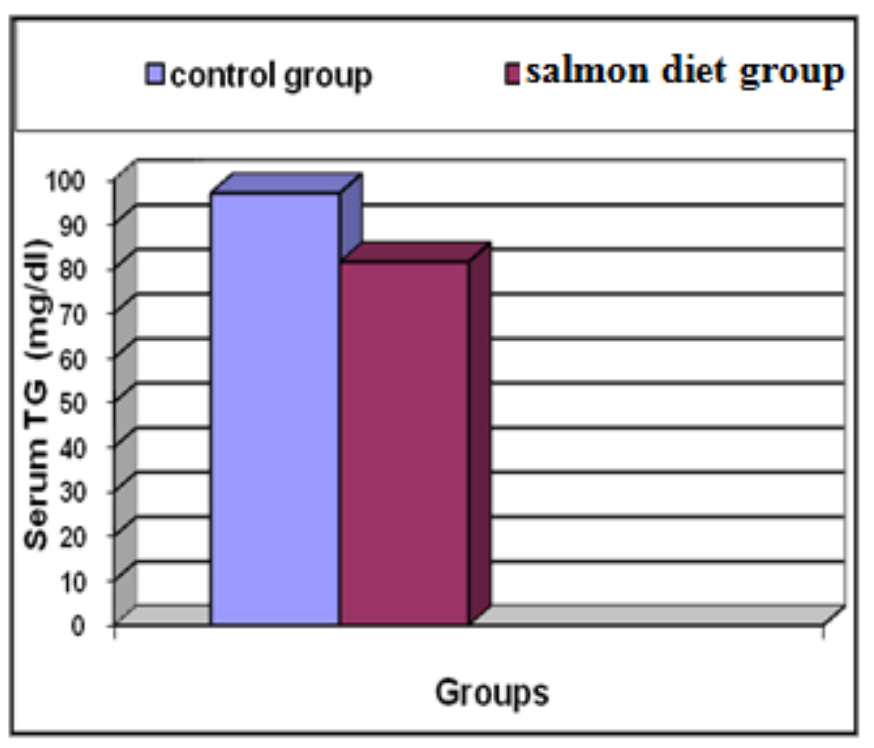

Fig (2b): Effect of salmon diet on TG level of female rats

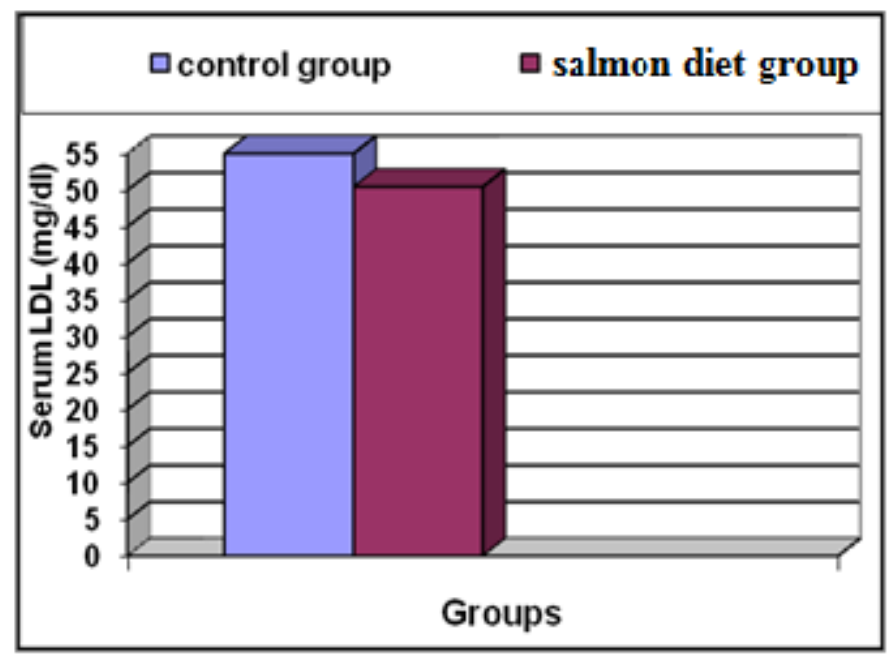

Fig (2d): Effect of salmon diet on LDL-C level of female rats

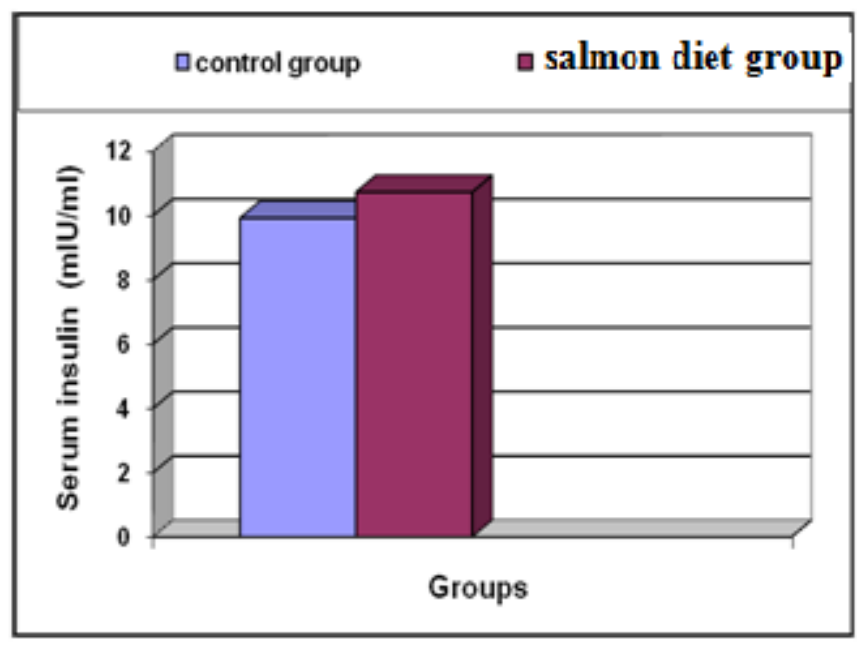

Fig (2f): Effect of salmon diet on insulin level of female rats 


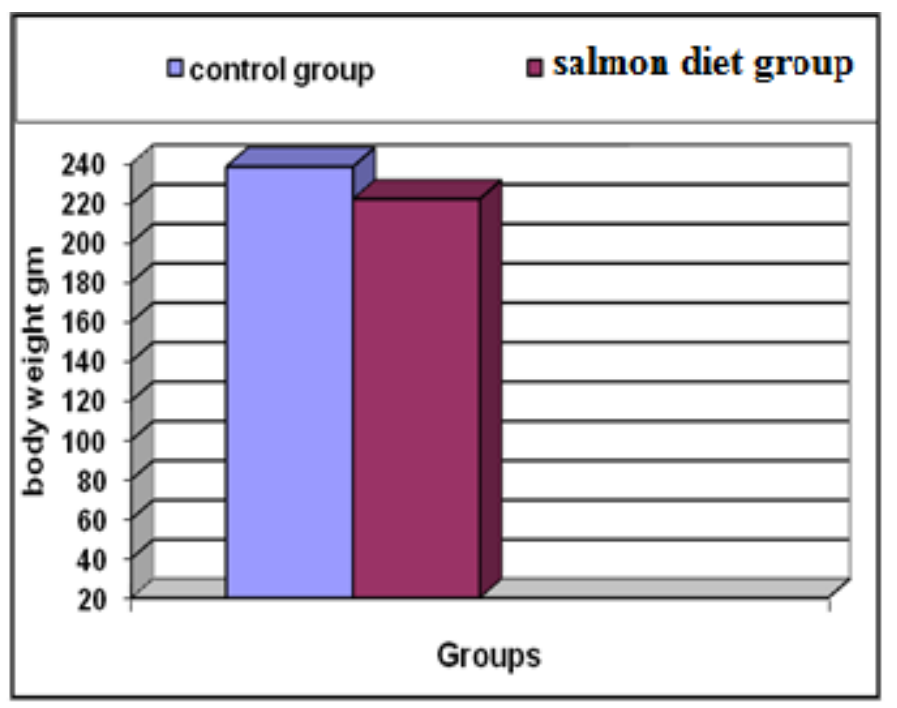

Fig (2e): Effect of salmon diet on body weight of female rats

\section{Discussion}

The present study showed significant reduction in serum level of TC in male and female rats fed salmon diet for three months compared with control groups. These results correlated with previous studies showing that administration of $n-3$ resulted in significant reduction of plasma TC concentration after a one month feeding trial in mice (Magdeldin et al., 2009). Studies on human also correlated with our study and showing that feeding diet enriched in n-3 PUFAs decreased plasma TC level compared to n-6 PUFAs rich diet (Eid et al., 2006). However, the present study conflicts those of Balk et al. (2006) who compared the effect of fish oil n-3 and plant-source oil n-3 on serum TC and found no effect.

The different results may be due to variations in the dosage, type of n-3 PUFAs and the control diets used, as well as the duration of the feeding period.

The possible explanation for the reduction of serum cholesterol by omega-3 may be due to its ability to deactivate farnesoid $\mathrm{X}$ receptor (FXR). One of the primary functions of FXR activation is the suppression of cholesterol 7 alpha-hydroxylase (CYP7A1), the rate-limiting enzyme in bile acid synthesis from cholesterol (Zhao et al., 2004).

In addition, omega-3 fatty acids are natural legends for some metabolic nuclear receptors including peroxisome proliferator- activated receptors (PPARs). Activation of these receptors by EPA and DHA resulted in suppression of lipid synthesis and promote mitochondria fatty acids beta oxidation in liver and muscle (Davidson, 2006 and Magdeldin et al., 2009).

Another theory to explain omega-3 cholesterol-lowering properties has been attributed to diminished sterol receptor element-binding protein $[$ SREBP] $-1 \mathrm{c}$ which control the expression of target 
genes for hepatic cholesterol, fatty acid- and TG synthesize enzymes (Sampath \& Ntambi, 2005 and Bays et al., 2008).

The cholesterol lowering effect of n-3 PUFAs has been suggested to be due to increased cholesterol catabolism, reduced cholesterol biosynthesis and increased biliary excretion of cholesterol (Du et al., 2003 and Oh et al., 2009). They also added that feeding diet high in n-3 PUFAs to adult mice also inhibit 3-hydroxy-3-methyl-glutaryl-CoA reductase (HMG-Co A) leading to reduced serum cholesterol level compared to an n-6 PUFAs diet.

Other studies found that cholesterol lowering effect of salmon fish protein diet compared to casein diet in rodents may be due to decreased intestinal absorption concomitant with increased hepatic excretion of cholesterol and bile (Hosomi et al., 2011 and Liaset et al., 2011).

Our study showed that serum level of TG in male and female rats fed salmon diet for three months decreased compared with control groups. These results agree with Zampolli et al. (2006) who reported a lower TG level in the fish oil fed group rich in n-3 PUFAs compared to the corn oil fed group rich in n-6 PUFAs after 20 weeks of dietary exposure in mice.

On the other hand Riediger et al. (2008) showed no significant differences in plasma TG levels between n-3 PUFA and n-6 PUFA fed groups after 4 weeks of dietary exposure in mice.

Therefore, a longer dietary exposure (more than 4 weeks) may be required to observe the TG lowering effects of n-3 PUFA.

Harris \& Bulchandani (2006) interpreted the decreased in TG by the ability of n-3 to decreased free fatty acid delivery to the liver or decreased hepatic fatty acids synthesis, increased phospholipids synthesis, and decreased activity of triglyceride-synthesizing enzymes as phosphatidic acid phosphatase/ phosphohydrolase (PAP) and diacylglycerol acyltransferase (DGAT) both are key enzymes involved in TG synthesis in the liver.

Also Bays et al. (2008) interpreted hypotriglyceridemic effect of n-3 is due to the ability of omega-3 fatty acids to reduce the incorporation of TG into VLDL particles and ultimately reduce TG secretion. They also added that one therapeutic option to lower TG level is omega-3 fatty acids P-OM3 drug (4 gm/day for $\geq 6$ weeks) which significantly reduces TG levels in subjects with severe hypertriglyceridemia.

Omega -3 may also lower triglyceride level by enhancing triglyceride clearance from circulating VLDL (lipoprotein responsible for transporting TG) through increased lipoprotein lipase activity. This 
may be mediated through a reduction in Apolipoprotein C-III (apo CIII) which inhibits lipoprotein lipase activity (Davidson et al., 2009).

We also found significant increase in serum HDL level in male rats and non significant increase in female rats fed salmon diet for three months compared with control groups. Such changes contribute to improve the catabolism of triglyceride-rich lipoproteins, leading to a substantial increase in HDLcholesterol level (Despres $\boldsymbol{e t}$ al., 2004). This result is in harmony with those obtained by Engler $\boldsymbol{e t}$ al . (2004) and Dawczynski et al. (2010) who found that n-3 PUFAs intake was associated with increased HDL-C in healthy volunteers. Previously it was suggested that PUFAs metabolism is affected by sex hormones (Extier et al., 2010), therefore differential effects observed in male and female rats.

Present study found no effect of salmon fish diet on fasting serum glucose and insulin levels in male and female rats. This is support by Balk et al. (2006) who reported a non-significant change in fasting glucose after consumption of n-3 and with Griffin et al. (2006) who observed no effect of n-3 on serum glucose and insulin or insulin sensitivity in healthy individuals. On the other hand, Breslow (2006) observed that composition of fish oil at $3 \mathrm{gm} /$ day cause hyperglycemia. This result may be due to high dose, at $>3 \mathrm{gm} /$ day gastrointestinal upset, clinical bleeding, fishy aftertaste, worsening hyperglycemia, and increased LDL cholesterol (Kris-Etherton et al., 2002)

The present study showed no significant effect of salmon diet on serum LDL level in male and female rats compared with control groups. The present data on rat's LDL coincide with Finnegan $\boldsymbol{e t}$ al. (2003) who found no effect of plant- and marine-derived n-3 PUFAs on serum LDL.

The present study showed no effect of salmon diet on body weight. These results correlated with, Dziedzic et al. (2007) who observed no effect of n-3 on body weight. Also, study in mice showed no effect of fish oil on body weight (Riediger et al., 2008).

\section{References}

Arab-Tehrany,E.; Jacquot,M.;Gaiani, C.; Imran, N.; Desobry, S. and Linder, M. (2012): Beneficial effects and oxidative stability of omega-3 long-chain polyunsaturated fatty acids. $\mathrm{J}$. Trends in Food Scien. \& Technol., 25: 24-33.

Australian Institute of Health and Welfare (AIHW) (2001): Heart, stroke and vascular diseases: Australian facts. Cardiovascular Disease Series No. 14 Cat. No. CVD 13. Canberra. ISSN 13239236 
Balk, E.M.; Lichtenstein, A.H.; Chung, M.; Kupelnick, B.; Chew, P. and Lau, J. (2006): Effects of omega-3 fatty acids on serum markers of cardiovascular disease risk: a systematic review. Atherosclerosis, 189:19-30.

Bays, H.E.; Tighe, A.P.; Sadovsky, R. and Davidson, M.H. (2008) : Prescription omega-3 fatty acids and their lipid effects: Physiologic mechanisms of action and clinical implications. Expert. Rev. Cardiovasc. Ther. 6: 391-409.

Bratu, A.; Mihalache,M.; , Anamaria Hanganu,A.; Chira,N.A.; Todasca,M.c. and Rosca,S. (2013): Quantitative determination of fatty acids from fish oils using GC-MS method and $1 \mathrm{H}-$ NMR spectroscopy. J. Sci. Bull., Series B, 75: 1454-2331.

Breslow, J. L. (2006): n-3 fatty acids and cardiovascular disease. Am. J. Clin. Nutr., 83:1477-1482.

Courtney, M.G.R. (2013): Determining the Number of Factors to Retain in EFA: Using the SPSS RMenu v2.0 to Make More Judicious Estimations. A peer reviewed J., 18: 1-14.

Davidson, M.H. (2006): Mechanisms for the hypotriglyceridemic effect of marine omega-3 fatty acids. Am. J. Cardiol., 98: 27 -33.

Davidson, M.H.; Maki, K.C.; Bays, H.E.; Bays, H.; Carter, R. and Ballantyne, C.M. (2009): Effects of prescription omega-3-acid ethyl esters on lipoprotein particle concentrations, apolipoproteins $\mathrm{AI}$ and CIII, and lipoprotein associated phospholipase $\mathrm{A}_{2}$ mass in statin-treated subjects with hypertriglyceridemia. J. Clin. Lipidol., 3:442-340.

Dawczynski, C.; Martin, L.; Wagner, A. and Jahreis, G. (2010):n-3 LC-PUFA-enriched dairy products are able to reduce cardiovascular risk factors: a double-blind, cross-over study. Clin. Nutr., 29:592-599.

DeFina, L.F.; Marcoux, L.G.; Devers, S.M.; Cleaver, J.P. and Willis, B.L. (2011): Effects of omega-3 supplementation in combination with diet and exercise on weight loss and body composition. Am. J. Clin. Nutr., 93:455-462.

Despres, J.P.; Lemieux, I. and Robins, S.J. (2004): Role of fibric acid derivatives in the management of risk factors for coronary heart disease. J. Drugs, 64:2177-2198.

Du, C.; Sato, A.; Watanabe, S.; Wu, C.Z.; Ikemoto, A.; Ando, K.; Kikugawa, K.; Fujii, Y. and Okuyama, H. (2003) : Cholesterol synthesis in mice is suppressed but lipofuscin formation is not affected by long-term feeding of n-3 fatty acid-enriched oils compared with lard and n-6 fatty acid-enriched oils. J. Biol. Pharm. Bull., 26:766-770. 
Dziedzic, B.; Szemraj, J.; Bartkowiak, J. and Walczewska, A. (2007): Various dietary fats differentially change the gene expression of neuropeptides involved in body weight regulation in rats. J. Neuroendocrinol., 19: 364-373.

Eid, H. M. A.; Arnesen, H.; Hjerkinn, E. M.; Lyberg, T.; Ellingsen, I. and Seljeflot, I. (2006): Effect of diet and omega-3 fatty acid intervention on asymmetric dimethylarginine. Nutr. Metab., 3: 3-4.

Engler, M.M.; Engler, M.B.; Malloy, M.; Chiu, E.; Besio, D.; Paul, S.; Stuehlinger, M. ; Morrow, J.; Ridker, P.; Rifai , N. and Mietus-Snyder, M. (2004): Docosahexaenoic acid restores endothelial function in children with hyperlipidemia: results from the EARLY study. Int. J. Clin. Pharmacol. Ther., 42: 672-679.

Extier, A.; Langelier, B.; Perruchot, M.H.; Guesnet, P.; Van Veldhoven, P.P.; Lavialle, M. and Alessandri, J.M. (2010): Gender affects liver desaturase expression in a rat model of n-3 fatty acid repletion. J. Nutr. Biochem., 21:180-187.

Finnegan, Y.E.; Minihane, A.M.; Leigh-Firbank, E.C.; Kew， S.; Meijer， G.W.; Muggli, R.; Calder, P.C. and Williams, C.M. (2003): Plant- and marine-derived n-3 polyunsaturated fatty acids have differential effects on fasting and postprandial blood lipid concentrations and on the susceptibility of LDL to oxidative modification in moderately hyperlipidemic subjects. Am. J. Clin. Nutr., 77:783-795.

Flachs, P.; Rossmeisl, M. and Kopecky, J. (2014): The effect of n-3 fatty acids on glucose homeostasis and insulin sensitivity. Physiol. Res., 63: S93-S118.

Gordon, T.; Castelli, W.P.; Hjortland, M.C.; Kannel, W.B. and Dawber, T.R. (1977): High density lipoprotein as a protective factor against coronary heart disease. The Framingham Study. Am. J. Med., 62:707-714.

Griffin, M.D.; Sanders, T.A.; Davies, I.G.; Morgan, L.M.; Millward, D.J.; Lewis, F.; Slaughter, S.; Cooper, J.A.; Miller, G.J. and Griffin, B.A. (2006): Effects of altering the ratio of dietary n-6 to n-3 fatty acids on insulin sensitivity, lipoprotein size, and postprandial lipemia in men and postmenopausal women aged 45-70 y: the OPTILIP Study. Am. J. Clin. Nutr.; 84:1290-1298.

Harris, W.S. And Bulchandani, D. (2006): Why do omega-3 fatty acids lower serums triglycerides?. J. Curr. Opin. Lipidol., 17:387-393. 
Hosomi, R.; Fukunaga, K.; Arai, H.; Kanda, S.; Nishiyama, T. and Yoshida, M. (2011): Fish protein decreases serum cholesterol in rats by inhibition of cholesterol and bile acid absorption. J. Food Sci., 76:H116-H121.

Judzewitsch, R.G.; Pfeiffer, M.A.; Best, J.D.; Beard, J.C.; Halter, J.B. and Porte, D. (1982): Chronic chlorpropamide therapy of non insulin-dependent diabetes augments basal, and stimulated insulin secretion by increasing islet sensitivity to glucose. J. Clin. Endocrinol. Metab., $55: 321-328$.

Kelley, D.S.; Siegel, D.; Vemuri, M. and Mackey, B.E. (2007): Docosahexaenoic acid supplementation improves fasting and postprandial lipid profiles in hypertriglyceridemic men. Am. J. Clin. Nutr., 86:324-333.

Kolakowska, A.; Zienkowicz, L.; Domiszewski, Z., and Bienkiewicz, G. (2006): Lipid charges and sensory quality of whole and gutted rainbow trout during storage in ice. Acta Ichthyologica et Piscatoria, 36: 39- 47.

Koubaa, A.; Mihoubi,N.B.; Abdelmouleh, A. and Bouain, A. (2012): Comparison of the effects of four cooking methods on fatty acid profiles and nutritional composition of red mullet (Mullus barbatus) muscle. J. Food Sci. and Biotechnology, 21: 1243-1250.

Kris-Etherton, P.M.; Harris, W.S. and Appel, L.J. (2002): Fish consumption, fish oil, omega-3 fatty acids, and cardiovascular disease. J. Circulation, 106:2747-57.

Liaset, B.; Hao, Q.; Jorgensen, H.; Hallenborg, P.; Du, Z.Y.; Ma, T.; Marschall, H.U.; Kruhoffer, M.; Li, R.; Li, Q.; Yde, C.C.; Criales, G.; Bertram, H.C.; Mellgren, G.; Ofjord, E.S.; Lock, E.J.; Espe, M.; Froyland, L.; Madsen, L. and Kristiansen, K. (2011): Nutritional regulation of bile acid metabolism is associated with improved pathological characteristics of the metabolic syndrome. J. Biol. Chem., 286: 28382-28395.

Lu, J.; Borthwick, F.; Hassanali, Z.; Wang, Y.; Mangat, R.; Ruth, M.; Shi, D.; Jaeschke, A.; Russell, J.C.; Field, C.J.; Proctor, S.D. and Vine, D.F. (2011): Chronic dietary n-3 PUFA intervention improves dyslipidaemia and subsequent cardiovascular complications in the JCR:LA- cp rat model of the metabolic syndrome. Br. J. Nutr., 105:1572-1582.

Magdeldin, S.; Elewa, Y.; Ikeda, T.; Ikei, J.; Zhang, Y.; Xu, B.; Nameta, M.; Fujinaka, H.; Yoshida, Y.; Yaoita, E. and Yamamoto, T. (2009): Dietary supplementation with arachidonic acid but not eicosapentaenoic or docosahexaenoic acids alter lipids metabolism in C57BL/6J mice. J. Gen. Physiol. Biophys., 28: 266-275. 
Micallef, M.; Munro, I.; Phang, M. and Garg, M. (2009): Plasma n-3 Polyunsaturated Fatty Acids are negatively associated with obesity. Br. J. Nutr., 102:1370-1374.

Moore, C.S.; Bryant, S.P.; Mishra, G.D.; Krebs, J.D.; Browning, L.M.; Miller, G.J. and Jebb, S.A. (2006): Oily fish reduces plasma triacylglycerols: a primary prevention study in overweight men and women. Nutr., 22: 1012-1024.

Morgado, N.; Rigotti, A. and Valenzuela, A. (2005): Comparative effect of fish oil feeding and other dietary fatty acids on plasma lipoproteins, biliary lipids and hepatic expression of proteins involved in reverse cholesterol transport in the rat. J. Ann. Nutr. Metab., 49: 397-406.

Munro, I.A. and Garg, M.L. (2013): Prior supplementation with long chain omega-3 polyunsaturated fatty acids promotes weight loss in obese adults: a double-blinded randomised controlled trial. J. Food Funct., 4:650-658.

Nuernberg, K.; Breier, B.H.; Jayasinghe, S.N.; Bergmann, H,; Thompson, N,; Nuernberg, G.; Dannenberger, D.; Schneider, F.; Renne, U.; Langhammer, M. and Huber, K. (2011) : Metabolic responses to high-fat diets rich in n-3 or n-6 long-chain polyunsaturated fatty acids in mice selected for either high body weight or leanness explain different health outcomes" Nutr Metab.,11: 8-56.

Oh, H.T.; Chung, M.J.; Kim, S.H.; Choi, H.J. and Ham, S.S. (2009): Masou salmon (Oncorhynchus masou) ethanol extract decreases 3-hydroxy-3-methylglutaryl coenzyme A reductase expression in diet-induced obese mice. J. Nutr. Res., 29:123-129.

Reeves, P.G. (1997): Components of the AIN-93 Diets as Improvements in the AIN-76A Diet. J. Nutr., 127: 838S-841S.

Riediger, N.D.; Othman, R.; Fitz, E.; Pierce, G.N.; Suh, M. and Moghadasian, M.H. (2008) : Low n-6:n-3 fatty acid ratio, with fish- or flaxseed oil, in a high fat diet improves plasma lipids and beneficially alters tissue fatty acid composition in mice. Eur. J. Nutr., 47:153-160.

Roeschlau, P.; Bernt, E. and Gruber, W.J. (1974): An investigation of the determination of serum cholesterol by an enzymatic way. Clin. Chem. Biochem., 12: 403-407.

Sampath, H. and Ntambi, J.M. (2005): Polyunsaturated fatty acid regulation of genes of lipid metabolism. J. Annu. Rev. Nutr., 25: 317-340.

Sanders, T.A.; Lewis, F.; Slaughter, S.; Griffin, B.A.; Griffin, M.; Davies, I.; Millward, D.J.; Cooper, J.A. and Miller, G.J. (2006): Effect of varying the ratio of n-6 to n-3 fatty acids 
by increasing the dietary intake of alpha-linolenic acid, eicosapentaenoic and docosahexaenoic acid, or both on fibrinogen and clotting factors VII and XII in persons aged 45-70 y: the OPTILIP study. Am. J. Clin. Nutr., 84 :513-522.

Simopoulos, A.P. (2002): The importance of the ratio of omega-6/omega-3 essential fatty acids. J. Biomed. Pharmacother., 56:365-379.

Skulas-Ray, A.C.; Kris-Etherton, P.M.; Harris, W.S.; Vanden-Heuvel, J.P.; Wagner, P.R. and West, S.G. (2011): Dose-response effects of omega-3 fatty acids on triglycerides, inflammation, and endothelial function in healthy persons with moderate hypertriglyceridemia. Am. J. Clin. Nutr., 93:243-252.

Stein, E.A. (1987): "Lipids, lipoproteins, and apolipoproteins in Tietz, N.W. (Eds), Fundamentals of Clinical Chemistry. 3rd ed. Saunders, W.B. Philadelphia, P.A., 448-481.

Taouis, M.; Dagou, C.; Ster, C.; Durand, G.; Pinault, M. and Delarue, J. (2002): n-3 Polyunsaturated fatty acids prevent the defect of insulin receptor signaling in muscle. Am. J. Physiol. Endocrinol. Metab., 282: E664-E671.

Tietz, N.W. (1995): Clinical guide to laboratory testes. $3^{\text {rd }}$ ed. Saunders, W.B. Philadelphia, P.A., 268273.

Vessby, B.; Uusitupa, M.; Hermansen, K.; Riccardi, G.; Rivellese, A.A.; Tapsell, L.C.; Nälsén, C.; Berglund, L.; Louheranta, A.; Rasmussen, B.M.; Calvert, G.D.; Maffetone, A.; Pedersen, E.; Gustafsson, I.B. and Storlien, L.H. (2001): Substituting dietary saturated for monounsaturated fat impairs insulin sensitivity in healthy men and women: The KANWU Study. Diabetol., 44:312-319.

Vijaimohan, K.; Jainu, M.; Sabitha, K.E.; Subramaniyam, S.; Anandhan, C. and Shyamala Devi, C.S.(2006) : Beneficial effects of alpha linolenic acid rich flaxseed oil on growth performance and hepatic cholesterol metabolism in high fat diet fed rats. J. Life Sci., 79:448-454.

Wang, S.; Wu, D.; Matthan, N.R.; Lamon-Fava, S.; Lecker, J.L. and Lichtenstein, A.H. (2009): Reduction in dietary omega-6 polyunsaturated fatty acids: eicosapentaenoic acid plus docosahexaenoic acid ratio minimizes atherosclerotic lesion formation and inflammatory response in the LDL receptor null mouse. J. Atherosclerosis, 204:147-155.

Watanabe, T. (2002): Strategies for further development of aquatic feeds. Fisheries Scien., 68: 242252. 
Weaver, K.L.; Ivester, P.; Chilton, J.A.; Wilson, M.D.; Pandey,P. and Chilton, F.H.(2008) : The content of favorable and unfavorable polyunsaturated fatty acids found in commonly eaten fish. J. Am. Diet. Assoc., 108: 1178-1185.

Zampolli, A.; Bysted, A.; Leth, T.; Mortensen, A.; De Caterina, R. and Falk, E. (2006): Contrasting effect of fish oil supplementation on the development of atherosclerosis in murine models. J. Atherosclerosis, 184: 78-85.

Zhao, A.; Yu, J.; Lew, J.L. Huang, L.; Wright, S.D. and Cui, J. (2004): Polyunsaturated fatty acids are FXR ligands and differentially regulate expression of FXR targets. DNA Cell Biol., 23: 519526.

Zheng, T.; Zhao, J.; Wang, Y.; Liu, W.; Wang, Z.; Shang, Y.; Zhang, W.; Zhang, Y. and Zhong, M. (2014): The limited effect of omega-3 polyunsaturated fatty acids on cardiovascular risk in patients with impaired glucose metabolism: a meta-analysis. Clin. Biochem., 47: 369-377.

Zhou, Q.C.; Tan, B.P.; Mai, K.S. and Liu, Y.J. (2004): Apparent digestibility of selected feed ingredients for juvenile cobia Rachycentron canadum. J. Aquaculture., 241:441-451. 